\title{
Selenium: a brief review and a case report of selenium responsive cardiomyopathy
}

\author{
Abdulrahman Al-Matary ${ }^{1 *}$, Mushtaq Hussain ${ }^{1,2}$ and Jaffar Ali ${ }^{3,4}$
}

\begin{abstract}
Background: The authors review the role of selenium and highlight possible low selenium levels in soil that may result in deficient states in Saudi Arabia.

Case presentation: The authors report a case of selenium-responsive cardiomyopathy in a 15-month old Saudi Arabian boy. This case of selenium deficiency causing dilated cardiomyopathy is presented with failure to thrive, prolonged fever and respiratory distress. The investigations revealed selenium deficiency. Selenium supplementation along with anti-failure therapy [Furosimide, Captopril] was administered for 6 months. Following therapy the cardiac function, hair, skin and the general health of the patient improved significantly.

Conclusion: The patient with dilated cardiomyopathy of unknown etiology, not responding to usual medication may be deficient in selenium. Serum selenium measurements should be included in the diagnostic work-up to ensure early detection and treatment of the disease. The selenium level in the Saudi population needs be determined. Vulnerable populations have to undergo regular selenium measurements and supplementation if indicated. Dependence on processed foods suggests that the Saudi population fortify themselves with nutrient and micronutrient supplements in accordance to the RDA.
\end{abstract}

Keywords: Dilated cardiomyopathy, Glutathione, Peroxidase, Keshan disease, Selenoproteins, Selenium deficiency, Micronutrients deficiency

\section{Background}

Selenium is an essential trace element in humans and animals. It is known for its potent antioxidant activity. Selenium is vital for good health [1-5]. Al-Saleh and coworkers [6] measured selenium in 300 umbilical cord blood samples collected from healthy pregnant women in Al-Kharj area in Saudi Arabia which showed serum selenium levels of $40.847 \pm 8.969 \mu \mathrm{g} / \mathrm{L}$ in 300 newborns. Of interest, the cord serum selenium level was significantly lower in preterm infants than full-term infants $(32 \pm 8.029 \mu \mathrm{g} / \mathrm{L}$ versus $41.323 \pm 8.784 \mu \mathrm{g} / \mathrm{L})$. They also noted a significant positive correlation between selenium levels and birth weight. Their findings suggest that low selenium levels in newborns reflect an inadequate maternal dietary intake. Another study performed on Saudi Arabian patients suffering from dilated cardiomyopathy showed that while no link could be established between

\footnotetext{
* Correspondence: aalmatary@kfmc.med.sa

'Department of Neonatology, King Fahad Medical City, Riyadh, Kingdom of Saudi Arabia

Full list of author information is available at the end of the article
}

plasma selenium levels and the disease, the level of selenium in the supposedly healthy controls was at the lower end of the normal range and the test group only marginally lower than the control group [7]. In two other studies performed in the AlKharj area of Saudi Arabia by Al-Saleh et al. [8,9] noted that $41 \%$ of 737 adults [8] and $53.4 \%$ of 513 children [9] had toenail selenium levels lower than $0.56 \mu \mathrm{g} / \mathrm{g}$ that are considered low but not deficient $(<0.46 \mu \mathrm{g} / \mathrm{g})$. Much earlier, studies performed by the same authors [10,11] on selenium levels in wheat grown in various parts of Saudi Arabia and, the soil, alfalfa and water in farms in AlKharj area of Saudi Arabia showed selenium levels to be insufficient in wheat grains of 7 of 8 regions in Saudi Arabia and very low in soil specimens. Importantly, the very low levels of selenium were found in the soil in the Keshan region of China, where selenium deficiency was thought to be the etiologic factor responsible for endemic dilated cardiomyopathy or Keshan disease [12,13] prevalent in that region. Indeed selenium deficiency is now well 
recognized as the causative factor implicated in the etiology of Keshan disease [14] in China.

This suggests that the Saudi population in the AlKharj region and possibly in the rest of Saudi Arabia could be at risk of selenium deficiency. The toenail selenium levels seen in Saudi Arabia were reflective of low but not deficient levels probably because unlike the Chinese of Keshan province the Saudis consume imported foodstuff, practice different lifestyles and their higher socioeconomic conditions probably help maintain their selenium levels within the normal range albeit at its lower end. This plus the findings of insufficient selenium observed in wheat grains grown in 7 of 8 regions of Saudi Arabia suggest that marginal selenium deficiency could be endemic in Saudi Arabia and that the deficient state could manifest in some isolated segments of the Saudi society. Selenium therefore deserves to be investigated in greater detail and such knowledge could assist in the diagnosis and resolution of disease conditions peculiar to selenium deficiency. Selenium is perhaps a hitherto neglected entity but possibly a crucial factor affecting the Saudi population. It is known to be essential for a vast number of normal physiologic activities and for the maintenance of good health. Therefore, its deficiency is implicated in an array of disease states which are discussed in this brief review.

Major dietary sources of selenium are plant foods (provided the soil is not deficient in selenium), animal kidneys, seafood, egg yolk and Brazil nuts $[1,15,16]$. Besides, the soil selenium level is reflected in the concentrations seen in plants [17]. Parenteral and enteral nutrition are iatrogenic causes of selenium deficiency. Selenium malabsorption, cystic fibrosis, rheumatoid arthritis, neoplasia, and other varied clinical disorders [18] exhibit low plasma levels of selenium.

Highest concentrations of selenium are found in Brazil nuts that provide 8 and 83 g Selenium/g [15]. Consumption of one and up to a maximum of two Brazil nuts per day (estimated to contain $\sim 100 \mathrm{~g}$ of selenium) [15] may help to meet daily requirements. However, consumption of more than two Brazil nuts per day may contribute to selenium toxicity due to accumulation of selenium. In particular, high selenium exposure may be associated with defective glucose and lipid metabolism [19] and could lead to diabetes and hyperlipidemia.

Since the early 1900 s selenium has been regarded as possessing anticancer properties [20]. It has been found to inhibit DNA damage in vitro, and reduce pulmonary metastasis and radiation-induced carcinogenesis in vivo [21-24]. There appears to be an association between selenium levels and risk of lung cancer [25]. Besides anticancer properties, selenium has a number of functions in the normal cardiovascular [26-28], reproductive [29-32], gastroenterological [33,34], hepatic [35] and immune systems [3,36,37]. In addition, new roles of selenium are being discovered [2,4,15,36,38-40].

Selenium in the form of various selenoproteins is involved in the human antioxidant systems [41]. The numbers of selenoproteins known to be operating in the human include at least 25 and up to 30 selenoproteins, including glutathione peroxidase, thioredoxin reductase, iodothyronine deiodinase, and selenoproteins $\mathrm{P}, \mathrm{W}$, and $\mathrm{R}[42,43]$. It is now well documented that these enzymes protect against free radical damage. They also regulate DNA transcription and cell proliferation. Selenium exerts its chemopreventive effect through the glutathione and thioredoxin systems [41], while some investigations suggest protective effects against allergies [44], and asthma [45], the other studies could not find a correlation between selenium and asthma [46]. In addition, recent studies suggest growth inhibitory and proapoptotic activity for selenometabolites in premalignant cells [47]. It is fairly well recognized that selenium is also involved in thyroid function, T-cell immunity, and spermatogenesis [48]. It is also known to be a competitive antagonist of heavy metals such as arsenic and cadmium $[49,50]$ that are potentially carcinogenic. Besides, selenium deficiency could predispose the affected individual to a number of diseases [51]. Selenium deficiency could predispose to viral infections or cause a depletion of selenium or both [3,37] as a consequence of which certain disease states could manifest such as cardiomyopathy (Coxsackie virus) or immunosuppression as in HIV-induced AIDS [52]. In particular, selenium deficiency in patients with HIV infection may be due to the trapping of selenium by a selenoprotein encoded by the proviral genome [53].

Numerous reports $[14,18,51,54]$ have implicated selenium deficiency in cardiovascular diseases, including studies from Saudi Arabia [26,27], but other studies $[39,55,56]$ including one study from Saudi Arabia [28] have been inconclusive. Congestive cardiomyopathy or skeletal- muscle disorders may also develop in patients with selenium deficiency [57].

Here the authors highlight the possible presence of low levels and possibly deficient states of selenium in the Saudi population. The authors report a case in point of selenium-responsive cardiomyopathy in a 15-month old Saudi Arabian boy. It is crucial to bear in mind that selenium deficiency could be the underlying cause when confronted with cardiomyopathy. This is due to the fact that selenium levels in the Saudi soil and therefore in its produce could be low. Indeed the level of selenium intake [26] and its level in the tested segments of the Saudi population appear to be low [7-9,26-28] as reviewed in this report. The early identification of selenium deficiency in dilated cardiomyopathy is imperative for the prevention and 
reversal of its deleterious effects on the myocardium $[58,59]$.

\section{Case presentation}

A 15 months old Saudi boy from the Al Qassem area of Saudi Arabia was presented with prolonged fever (6 months) and shortness of breath for two weeks. He had a history of chronic diarrhea and had lost $2 \mathrm{~kg}$ of weight in the previous 8 months. The patient presented with signs of congestive heart failure; labored breathing, tachypnea, poor appetite, weight loss, hepatomegaly and required anti-failure medications (Captopril and Furosemide). While these two medications helped to relieve the patient of his symptoms, they did not treat the underlying cause of the condition. Echocardiography (Figure 1) revealed dilated cardiomyopathy. He was born full term following normal spontaneous vaginal delivery. His birth weight was $3.4 \mathrm{~kg}$. He was the $5^{\text {th }}$ sibling of non-consanguineous parents. His antenatal and post natal life periods were uneventful. There was no family history of any known chronic illnesses or unexplained death. He received breast-feeding exclusively for one year. He started sitting at 6 months of age and his development, weight and length were appropriate until six months prior to his presentation. Soon after six months of age he stopped to thrive due to ongoing illness. He had asthma which was controlled by ventolin and flixotide.

Investigations undertaken were his metabolic profile (serum ammonia, lactate, newborn screening, urine orgnic acid, tendem mass spectrophotometry (MS), serum carnitine level, organic acid gas chromatography-mass spectrophotometry (GC-MS), immunological profile [immunoglobulin level, oxidative burst test, lymphocytes markers], thyroid function tests, sweat chloride test, stool alpha 1 antitrypsin, celiac profile, bone profile, liver function test, coagulation profile, complete blood count, erythrocyte sedimentation rate (ESR), lipid profile, serum albumin, small intestinal biopsy, Magnetic Resonance imaging (MRI) brain. All

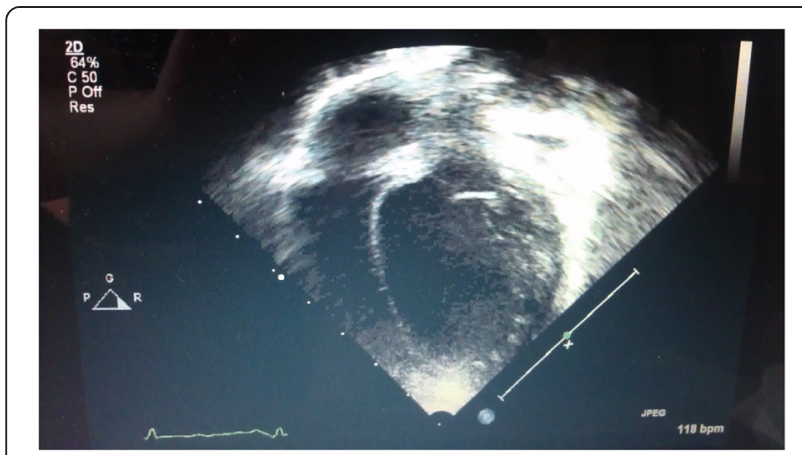

Figure 1 Echocardiography of a 15-month male infant with dilated myocardiopathy. were within normal limits, however his serum selenium level was very low $[9.1 \mu \mathrm{g} / \mathrm{l}$ (measured by inductively coupled mass spectrophotometry); normal range: 55$103 \mathrm{~g} / \mathrm{l}]$. Interaction of selenium with other micronutrients was not investigated because thyroid function tests were normal and clinically there appeared to be no concern of iodine or vitamin E deficiency including that of other micro nutrients.

Selenium supplement (by the standard $2 \mu \mathrm{g} / \mathrm{kg} / \mathrm{day}$ which is well documented) was commenced per os and was administered for about 6 months. His diarrhea, infections, failure to thrive, cardiomyopathy was managed in collaboration with the pediatric cardiology, gastroenterology, metabolic, neurology and nutritional units of the hospital. He was followed up in out-patient department.

Improvement was observed following these interventions. He gained weight. Positive changes were noted for his skin, hair and general health as evidenced by signs and symptoms and echo images. Repeat echocardiography was apparently normal following selenium treatment (Figure 2). He also demonstrated improved appetite, neurological and cardiac functions (ejection fraction was from 40 to $80 \%$ ). The patient responded to selenium supplementation within 3-4 months. His selenium levels were repeatedly measured at 3 and 6 months following selenium supplementation that revealed normalized selenium levels (94/L).

Written informed consent was obtained from the patient's parents for publication of this case report and any accompanying images. A copy of the written consent is available for review by the Editor of this journal.

\section{Conclusions}

The prevalence of selenium deficiency and low levels of selenium in the Saudi population is not known. The available literature shows that highly plausible diseases associated with selenium deficiency appear to be a distinct possibility due to the low levels of selenium found in the soil, alfalfa grass, and water, and as reflected in

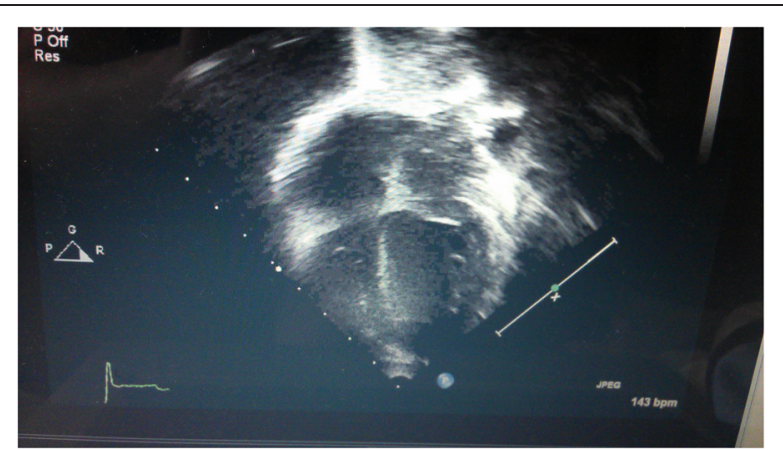

Figure 2 Apparently normal echocardiography after selenium therapy in a 15-month male infant. 
the toenails in the area tested $[6,8,9,11]$. Although the soil selenium levels could vary from place to place, the very fact that low soil selenium exists in a given sector of Saudi Arabia suggests that it could likewise exist in other parts of the country. However the fact that the Saudi population depends almost entirely on imported processed foods suggests that the selenium deficiency could well be due to imported processed foods rather than from soil but this remains to be elucidated. Likewise it is probable that the dependence of the Saudi population on imported processed foods could also lead to deficiency in other nutrients and micronutrients. Clinicians must consider selenium deficiency if the symptoms and clinical presentations are reminiscent of diseases associated with selenium deficiency. The present case report is a case in point.

Although, the first cases were reported in 1937 during an epidemic in a rural area of China called Keshan, hence the term Keshan Disease [60], it was not until 1971 that a correlation between selenium deficiency and this disease was established. The mechanism of its pathogenesis is thought to be due to viral infection of selenium deficientcy-induced weakened cardiomyocytes [61]. It is well documented that selenium is an essential co-factor of the enzyme glutathione peroxidase (GPX). There are 8 isoforms of GPX selenoenzymes in humans, but only six (GPX1-6) contain selenium. A decrease in the activity of glutathione peroxidase enzyme secondary to selenium deficiency may lead to an increase in the oxidative stress in the myocardial cells, and this can make the cell more susceptible to Coxsackie virus or infection by other viruses. This mechanism was demonstrated in mice models by injecting viral genome in mice deficient in selenium as opposed to mice fed diet containing sufficient selenium. The incidence of myocarditis in the former was much higher [62]. Furthermore, selenium deficiency appears to increase the virulence of otherwise benign virus. Myocardial necrosis, dyspnea, early fatigue and even early or sudden death are associated with selenium deficiency. The time course for the development of congestive cardiac failure in affected individuals varies in the presence of viral infection between several hours in patients with Keshan disease to several years in patients on total parenteral nutrition [63].

Selenium deficiency is confirmed by measuring serum or plasma concentrations of selenium. Values lower than $70 \mathrm{ng} / \mathrm{mL}$ or $0.8 \mu \mathrm{mol} / \mathrm{L}$ suggest that synthesis of selenium-associated proteins is not optimal and selenium supplies are limited [64]. Hovewer, selenium deficiency on its own does not usually cause illness. It makes the body more vulnerable to diseases [65].

Selenium and or glutathione peroxidase level(s) may be indicated if there is no other possible reason, cause or explanation for dilated cardiomyopathy in children.
Selenium supplementation is indicated when it is below the normal range but should be discontinued when selenium levels are normalized. It may be worthwhile to determine the levels of selenium and other nutrients and micronutrients in the Saudi population due to the observation in a select Saudi community that selenium levels are on the border-line in the supposedly normal population (7). Moreover, it is recommended that regular selenium measurements are performed followed by supplementation if levels are below the normal range in selected vulnerable populations.

The dependence on imported processed foods in Saudi Arabia suggests that it may also be worthwhile to determine the levels of other nutrients including micronutrients in the Saudi population and common foods, since possible deficiencies of other nutrients and micronutrients could coexist with selenium deficiency. Until sufficient data is available to prove otherwise, the Saudi population should fortify themselves with nutrients and micronutrient supplements in keeping with the Recommended of Dietary Allowances (RDA) because processed foods may be deficient in nutrients and micronutrients.

In view of possible prevalence of low or deficient levels of selenium in the Saudi population it is imperative that selenium deficiency is considered when symptoms presentation is reminiscent of diseases associated with selenium deficiency. It is important the selenium level in the Saudi population is determined. Vulnerable populations have to be carefully monitored with regular selenium measurements and supplementation if indicated. Dependence on processed foods suggests that the Saudi population fortifies themselves with nutrient and micronutrient supplements in accordance to the RDA.

\section{Abbreviations}

ESR: Erythrocyte sedimentation rate; GC-MS: Gas Chromatography - Mass Spectrophotometry; GPX: Glutathione peroxidase; MRI: Magnetic resonance imaging; MS: Mass spectrophotometry; RDA: Recommended of Dietary Allowances.

\section{Competing interests}

The authors have no conflicts of interest whatsoever with regard to funding, commercial interests, etc. Authors declare no competing interests. No funding was sought for this work. No funding was received from any source other than routine operational budget that was not handled by the authors.

\section{Authors' contributions}

ARM contributed to the conceptualization, conduct of the study and wrote the first draft of the case report [40\%] $\mathrm{MH}$ provided the clinical aspects of the study [30\%] while JA reviewed the subject and re-wrote the manuscript [30\%]. All authors read and approved the final manuscript.

\section{Acknowledgement}

The authors express gratitude to Dr. Ali Alasmari Pediatric Metabolist and Dr. Omar Galal, Pediatric Cardiologist, for their assistance in this case study.

\section{Author details}

${ }^{1}$ Department of Neonatology, King Fahad Medical City, Riyadh, Kingdom of Saudi Arabia. ${ }^{2}$ Neonatal ICU, Mid Western Regional Maternity Hospital, Ennis 
Road, Limerick, Ireland. ${ }^{3}$ Department of Obstetrics and Gynaecology, Faculty of Medicine, University of Malaya, Kuala Lumpur, Malaysia. ${ }^{4}$ Stem Cell Unit, Department of Anatomy, College of Medicine, King Saud University, Riyadh, Saudi Arabia.

Received: 16 May 2012 Accepted: 27 February 2013 Published: 25 March 2013

\section{References}

1. Thomson CD, Robinson MF: Selenium in human health and disease with emphasis on those aspects peculiar to New Zealand. Am J Clin Nutr 1980, 33:303-323.

2. Rayman MP: The importance of selenium to human health. Lancet 2000, 356:233-241.

3. Beck MA, Matthews CC: Micronutrients and host resistance to viral infection. Proc Nutr Soc 2000, 59:581-585.

4. Papp LV, Lu J, Holmgren A, Khanna KK: From Selenium to Selenoproteins, Synthesis, Identity, and their Role in Human Health. Antioxid Redox Signal. 2000, 9(7):775-806

5. Mistry HD, Williams PJ: The importance of antioxidant micronutrients in pregnancy. Oxid Med Cell Longev. 2011, 2011:1-12.

6. Al-Saleh I, Al-Doush I: Ibrahim M \& Abdullah Rabbah Serum selenium levels in Saudi new-borns International. J Environ Health Res 1998, 8(4):269-275.

7. Raines DA, Kinsara AJ, Fawzy EM, Vasudevan S, Mohamed GE, Legayada ES, Al-Rawithi S, El-Yazigi A: Plasma and urinary selenium in Saudi Arabian patients with dilated cardiomyopathy. Biol Trace Elem Res 1999, 69(1):59-68.

8. Al-Saleh I, El-Doush I, Billedo G, Mohamed G-D, Yosef G: Status of selenium, vitamin $\mathrm{E}$, and vitamin $\mathrm{A}$ among Saudi adults, potential links with common endemic diseases. J Environ Pathol Toxicol Oncol 2007, 26(3):221-243.

9. Al-Saleh I, Billedo G, El-Doush I, El-Din Mohamed G, Yosef G: Selenium and vitamins status in Saudi children. Clin Chim Acta 2006, 368(1-2):99-109.

10. Al-Saleh IA, Al-Doush I: Selenium levels in wheat grains grown in Saudi Arabia. Bull Environ Contam Toxicol 1997, 59(4):590-594.

11. Al-Saleh IA, Al-Jaloud A, Al-Doush I, El-Din G: The distribution of selenium levels in Saudi dairy farms, a preliminary report from Al-Kharj. J Environ Pathol Toxicol Oncol 1999, 18(1):37-46.

12. Chen XS, Yang GQ, Chen JS, Chen XC, Wen ZM, Ge KY: Epidemiologic studies on the etiologic relationship of selenium and Keshan disease. Chin Med J [Engl] 1979, 92(7):477-482.

13. Yang GQ, Chen JS, Wen ZM, Ge KY, Zhu LZ, Chen XC, Chen XS: The role of selenium in Keshan disease. Adv Nutr Res 1984, 6:203-231.

14. Wei HL, Pei JR, Jiang CX, Zhou LW, Lan T, Liu M, Wang T: Analysis of glutathione peroxidase 1 gene polymorphism and Keshan disease in Heilongjiang Province. Genet Mol Res 2011, 10(4):2996-3001. China.

15. Thomson CD, Chisholm A, McLachlan SK, Campbell JM: Brazil nuts, an effective way to improve selenium status. Am J Clin Nutr 2008, 87:379-384.

16. Christophersen OA, Haug A: Animal products, diseases and drugs, a plea for better integration between agricultural sciences, human nutrition and human pharmacology. Lipids Health Dis 2011, 10:16

17. Keck A-S, Finley JW: Database values do not reflect selenium contents of grain, cereals, and other foods grown or purchased in the upper Midwest of the United States. Nutr Res 2006, 26:17-22.

18. Lockitch G: Selenium:clinical significance and analytical concepts. Crit Rev Clin Lab Sci 1989, 27(6):483-541.

19. Stranges S, Laclaustra M, Ji C, Cappuccio FP, Navas-Acien A, Ordovas JM, Rayman M, Guallar E: Higher selenium status is associated with adverse blood lipid profile in British adults. J Nutr 2010, 140(1):81-87.

20. Schrauzer GN, Surai PF: Selenium in human and animal nutrition, resolved and unresolved issues. A partly historical treatise in commemoration of the fiftieth anniversary of the discovery of the biological essentiality of selenium, dedicated to the memory of Klaus Schwarz [1914-1978] on the occasion of the thirtieth anniversary of his death. Crit Rev Biotechnol 2009, 29:2-9.

21. Knizhnikov VA, Shandala NK, Komleva VA, Knyazhev VA, Tutelyan VA: The effect of dietary levels of selenium on radiation resistance and radiationinduced carcinogenesis. Nutr Res 1996, 16:505-516.

22. Muecke R, Schomburg L, Glatzel M, Berndt-Skorka R, Baaske D, et al: Multicenter, Phase 3 Trial Comparing Selenium Supplementation With Observation in Gynecologic Radiation Oncology. Int J Radiat Oncol Biol Phys 2010, 78(3):828-835.
23. Li D, Graef GL, Yee JA, Yan L: Dietary supplementation with high-selenium soy protein reduces pulmonary metastasis of melanoma cells in mice. J Nutr 2004, 134:1536-1540.

24. Das A, Desai D, Pittman B, Amin S, El-Bayoumy K: Comparison of the chemopreventive efficacies of 1,4-phenylenebis(methylene) selenocyanate and selenium-enriched yeast on 4-(methylnitrosamino)-1(3-pyridyl)-1-butanoneinduced lung tumorigenesis in $\mathrm{A} / \mathrm{J}$ mouse. Nutr Cancer 2003, 46:179-185.

25. Zhuo H, Smith AH, Steinmaus C: Selenium and lung cancer, a quantitative analysis of heterogeneity in the current epidemiological literature. Cancer Epidemiol Biomarkers Prev 2004, 13:771-778.

26. Alissa EM, Ahmed WH, Al-ama N, Ferns GA: Selenium status and cardiovascular risk profile in healthy adult Saudi males. Molecules 2008, 31(14[1]):141-159.

27. Alissa EM, Bahjir SM, Ahmed WH, Al-Ama N, Ferns GA: Trace element status in Saudi patients with established atherosclerosis. J Trace Elem Med Biol 2006, 20(2):105-114.

28. Fawzy ME, El Yazigi A, Stefadouros MA, Raines DA, Kinsara AJ, Sivanandam $\mathrm{V}$, Mohamed GH, Galal O: The role of selenium deficiency in dilated cardiomyopathy in Saudi Arabia. Ann Saudi Med 1999, 19(1):20-22.

29. Mistry HD, Broughton Pipkin F, Redman CW, Poston L: Selenium in reproductive health. Am J Obstet Gynecol 2012, 206(1):21-30.

30. Boitani C, Puglisi R: Selenium, a key element in spermatogenesis and male fertility. Adv Exp Med Biol. 2008, 636:65-73.

31. Schneider $M$, Förster $H$, Boersma $A$, Seiler $A$, Wehnes $H$, Sinowatz F, Neumüller C, Deutsch MJ, Walch A, Hrabé De Angelis M, Wurst W, Ursini F, Roveri A, Maleszewski M, Maiorino M, Conrad M: Mitochondrial glutathione peroxidase 4 disruption causes male infertility. FASEB J 2009, 23(9):3233-3242.

32. Flohé L: Selenium in mammalian spermiogenesis. Biol Chem 2007, 388(10):987-995.

33. Kim JH, Kim BW, Kwon HJ, Nam SW: Curative effect of selenium against indomethacin-induced gastric ulcers in rats. J Microbiol Biotechnol 2011, 21(4):400-404

34. Kumar BS, Tiwari SK, Manoj G, Kunwar A, Amrita N, Sivaram G, Abid Z Ahmad A, Khan AA, Priyadarsini Kl: Anti-unlcer and antimicrobial activities of sodium selenite against Helicobacter pylori, in vitro and in vivo evaluation. Scand J Infect Dis 2010, 42(4):266-274.

35. Aboul-Soud MA, Al-Othman AM, El-Desoky GE, Al-Othman ZA, Yusuf K Ahmad J, Al-Khedhairy AA: Hepatoprotective effects of vitamin E/ selenium against malathion-induced injuries on the antioxidant status and apoptosis-related gene expression in rats. $J$ Toxicol Sci 2011, 36(3):285-296

36. Huang Z, Rose AH, Hoffmann PR: The Role of Selenium in Inflammation and Immunity, From Molecular Mechanisms to Therapeutic Opportunities. Antioxid Redox Signal. 2012, 16(7):705-743.

37. Beck MA: Antioxidants and viral infections, host immune response and viral pathogenicity. J Am Coll Nutr 2001, 20(5 Suppl):384S-388S. discussion 396S-397S.

38. Alissa EM, Bahiji SM, Ferns GA: The controversy surrounding selenium and cardiovascular disease, a review of the evidence. Med Sci Monit 2003, 9(1):RA9-RA18

39. Fritz H, Kennedy D, Fergusson D, Fernandes R, Cooley K, Seely A, Sagar S, Wong $R$, Seely D: Selenium and lung cancer, a systematic review and meta-analysis. PLoS One 2011, 6(11):e26259.

40. McKeever TM, Britton J: Diet and asthma. Am J Respir Crit Care Med 2004, 170(7):725-729.

41. Rayman MP: Selenium in cancer prevention, a review of the evidence and mechanism of action. Proc Nutr Soc 2005, 64:527-542.

42. Jablonska E, Gromadzinska J, Sobala W, Reszka E, Wasowicz W: Lung cancer risk associated with selenium status is modified in smoking individuals by Sep15 polymorphism. Eur J Nutr 2008, 47:47-54.

43. Abdulah R, Miyazaki K, Nakazawa M, Koyama H: Chemical forms of selenium for cancer prevention. J Trace Elem Med Biol 2005, 19:141-150.

44. Patelarou E, Giourgouli G, Lykeridou A, Vrioni E, Fotos N, Siamaga E, Vivilaki V, Brokalaki H: Association between biomarker-quantified antioxidant status during pregnancy and infancy and allergic disease during early childhood, a systematic review. Nutr Rev 2011, 69(11):627-641.

45. Hoffmann PR, Jourdan-Le Saux C, Hoffmann FW, Chang PS, Bollt O, He Q, Tam EK, Berry MJ: A role for dietary selenium and selenoproteins in allergic airway inflammation. J Immunol 2007, 179(5):3258-3267. 
46. Norton RL, Hoffmann PR: Selenium and asthma. Postepy Hig Med Dosw (Online) 2006, 60:624-631.

47. Ip C, Dong Y, Ganther HE: New concepts in selenium chemoprevention. Cancer Metastasis Rev 2002, 21:281-289.

48. Ashton K, Hooper L, Harvey LJ, Hurst R, Casgrain A, et al: Methods of assessment of selenium status in humans, a systematic review. Am J Clin Nutr 2009, 89:2025S-2039S.

49. Schrauzer GN: Selenium and selenium-antagonistic elements in nutritional cancer prevention. Crit Rev Biotechnol 2009, 29:10-17.

50. Khan MA, Wang F: Mercury-selenium compounds and their toxicological significance, toward a molecular understanding of the mercury-selenium antagonism. Environ Toxicol Chem 2009, 28:1567-1577.

51. [No authors listed]: Selenium. Monograp. Itern Med Rev 2003, 8(1):63-71.

52. Stone CA, Kawai K, Kupka R, Fawzi WW: Role of selenium in HIV infection. Nutr Rev 2010, 68(11):671-681.

53. Baum MK, Shor-Posner G, Lai S, et al: High risk of HIV-related mortality is associated with selenium deficiency. J Acquir Immune Defic Syndr Hum Retrovirol 1997, 15:370-374.

54. Zagrodzki P, Laszczyk P: Selenium and cardiovascular diseas. Postepy Hig Med Dosw (Online) 2006, 60:624-831 [Abst in English].

55. Lei C, Niu X, Ma X, Wei J: Is selenium deficiency really the cause of Keshan disease? Environ Geochem Health 2011, 33(2):183-188.

56. Marinescu V, McCullough PA: Nutritional and micronutrient determinants of idiopathic dilated cardiomyopathy, diagnostic and therapeutic implications. Expert Rev Cardiovasc Ther 1994, 9:1161-1170.

57. Dworkin BM: Selenium deficiency in HIV infection and the acquired immunodeficiency syndrome [AIDS]. Chem Biol Interact 1994, 91:181-186.

58. Levy JB, Jones HW, Gordon AC: Selenium deficiency, reversible cardiomyopathy and short-term intravenous feeding. Postgrad Med J 1994, 70:235-236

59. Kavaneau-McHugh AL, Ruff A, Perlamn E, Hutton N, Modlin J, Rowe S: Selenium deficiency and cardiomyopathy in acquired immunodeficiency syndrome. J Parenteral Nutr 1991, 15:347-349.

60. Li C: Selenium deficiency and endemic heart failure in China, a case study of biogeochemistry for human health. Ambio 2007, 36(1):90-93.

61. Lorgeril M, Salen P: Selenium and antioxidant defences as major mediaters in the development in the chronic heart failure. Heart Fail Rev Mar 2006, 11(1):13-17.

62. Beck MA, Handy J, Levander OA: The role of oxidative stress in viral infections. Ann N Y Acad Sci 2000, 917:906-912.

63. Yusuf SW, Rehman Q, Casscells W: Cardiomyopathy in association with selenium deficiency, a case report. JPEN J Parenter Enteral Nutr 2002, 26(1):63-96.

64. Institute of Medicine, Food and Nutrition Board: Dietary Reference Intakes, vitamin C, vitamin E, selenium, and carotenoids. Washington, D.C: National Academy Press; 2000.

65. Beck MA, Levander $\mathrm{O}$, Handy J: Selenium deficiency and viral infection. J Nutr 2003, 133:1463S-1467S.

doi:10.1186/1471-2431-13-39

Cite this article as: Al-Matary et al:: Selenium: a brief review and a case report of selenium responsive cardiomyopathy. BMC Pediatrics 2013 13:39.

\section{Submit your next manuscript to BioMed Central and take full advantage of:}

- Convenient online submission

- Thorough peer review

- No space constraints or color figure charges

- Immediate publication on acceptance

- Inclusion in PubMed, CAS, Scopus and Google Scholar

- Research which is freely available for redistribution 